\title{
Dispersal Patterns of Pine Wilt Disease in the Early Stage of Its Invasion in South Korea
}

\author{
Won Il Choi ${ }^{1,+}{ }^{\dagger}$, Hye Jung Song ${ }^{2,+}$, Dong Soo Kim ${ }^{3}$, Dae-Sung Lee ${ }^{4}$, Cha-Young Lee ${ }^{2}$, \\ Youngwoo Nam ${ }^{2}$, Joon-Bum Kim ${ }^{3}$ and Young-Seuk Park $4,5, *$ \\ 1 Warm Temperate and Subtropical Forest Research Center of National Institute of Forest Science, \\ Jeju 63582, Korea; wchoi71@korea.kr \\ 2 Division of Forest Insect Pests and Diseases, National Institute of Forest Science, Seoul 02455, Korea; \\ shj4621@naver.com (H.J.S.); ishursain06@korea.kr (C.-Y.L.); orangmania99@korea.kr (Y.N.) \\ 3 Southern Forest Resources Research Center of National Institute of Forest Science, Jinju 52817, Korea; \\ skimds@korea.kr (D.S.K.); jbkim1434@hanmail.net (J.-B.K.) \\ 4 Department of Biology, Kyung Hee University, Seoul 02447, Korea; dleotjd520@naver.com \\ 5 Department of Life and Nanopharmaceutical Sciences, Kyung Hee University, Seoul 02447, Korea \\ * Correspondence: parkys@khu.ac.kr; Tel.: +82-02-961-0946 \\ + These authors contributed equally to this work.
}

Received: 26 September 2017; Accepted: 25 October 2017; Published: 30 October 2017

\begin{abstract}
We characterized the dispersal patterns of pine wilt disease (PWD) in the early stage of its invasion in the South Korea, and estimated the influence of environmental factors on the dispersal of PWD. Data were obtained in 10 regions with at least five consecutive years of data for 10 years from 1994 to 2005. The dispersal patterns of PWD were categorized into four types: type 1 is a jumping type of dispersal, forming new patches; type 2 infestations are ones without any expansion of patch size; and types 3 and 4, respectively, show uni-directional or multi-directional dispersal outward from an existing patch. Dispersal patterns changed during different phases of the pathogen's invasion history: type 1 was the most frequent in the early invasion stage. Annual dispersal distance showed regional variations. Human population density had a positive correlation with the dispersal distance of PWD, indicating that anthropogenic factors can contribute to the dispersal of PWD. Our results suggested that dispersal through jumping from areas occupied by PWD was the main dispersal route in the early stage of invasion and that after this phase, the existing colonies expanded and merged. These results supported the existence of stratified dispersal patterns of PWD.
\end{abstract}

Keywords: pine wood nematode; forest disease; spatial dispersal; patch; invasion history; invasive species; stratified dispersal

\section{Introduction}

Invasive species are among the most severe disturbances affecting ecosystems due to their potentially devastating effects on natural communities [1]. The invasion process can be categorized into four steps: introduction, establishment, expansion, and naturalization [2]. After the successful establishment of an invasive species in a new area, it will continue to occupy the new habitat by expanding its range up to its ecological limits [2]. Thus, the best management strategy to control invasive species is to prevent their establishment in the initial stage of an invasion. If they are established, the next best strategy is to slow down their dispersal speed to minimize their impact on ecosystems. A USA national program to manage the gypsy moth (Lymantria dispar) called "slow the spread" is an example of the successful use of this approach [3]. The dispersal speed of gypsy moth was reduced through the eradication of isolated colonies that had formed beyond the population dispersal front of the infested zone [4]. 
Understanding the dispersal characteristics of a particular invasive species is essential to determining a suitable strategy to slow down its dispersal. Generally, invertebrates display a stratified dispersal based on the combination of long distance dispersal (LDD) and short distance dispersal (SDD) [5]. There are many examples of stratified dispersal including gypsy moth (L. dispar) [6], Argentine ant (Linepithema humile) [7], and mountain pine beetle (Dendroctonus ponderosae) [8].

Pine wilt disease (PWD), caused by the pine wood nematode (PWN), Bursaphelenchus xylophilus Nickle, a species native to North America, is one of the most serious threats to pine trees in Asia and Europe [9]. The PWN has invaded many Asian and European countries, including Japan in 1905 [10], China in 1982 [11], Korea in 1988 [2], Portugal in 1999 and Spain in 2008 [12]. The PWN is a tree-parasitic nematode and its length ranges from $0.6 \mathrm{~mm}$ to $1.0 \mathrm{~mm}$ [2]. It develops to a female or male adult through several stages including egg and four juvenile stages. The third juveniles enter the body of vectors such as Monochamus alternatus through the tracheal system. The PWN takes five days to complete a generation at $25{ }^{\circ} \mathrm{C}$ [2]. The nematode forms novel mutualistic relationships with native Monochamus species, vectors of PWN, allowing the nematode to quickly and safely move between pine trees and increasing the number of freshly killed trees available for the reproduction of Monochamus beetles [13]. The area damaged by PWN was 72 ha in 1988 and increased to 7811 ha in 2005 [2], indicating that the PWN has been in the range expansion phase. The dispersal distance of PWD depends on the dispersal capacity of Monochamus beetles. Several approaches have been used to measure the dispersal capacity of PWD, including analysis of field occurrence data [2], and flight-mill experiments [14]. Therefore, it is important to identify dispersal patterns of PWD as well as major environmental factors influencing the dispersal speed for the management of PWD [15].

The first occurrence of PWD in the South Korea was reported at Mt. Geumjong in Busan in 1988 [2] although it is suspected that PWD invaded Korea before 1986 [16]. Until 1997, distribution of PWN was restricted to the Busan area. Before the first detection of PWN on Korean white pine (Pinus koraiensis Siebold et Zuccarini) near Seoul in 2006, Japanese red pine (Pinus densiflora Siebold et Zuccarini), and Japanese black pine (Pinus thunbergii Parlatore) were known to be host plants for pine wilt nematode. The Japanese pine sawyer, Monochamus alternates Hope, is the PWN vector for these two pine species, whereas Monochamus saltuarius Gebler is the vector for Korean white pine.

This study aims to characterize the dispersal patterns of PWD at both the stand (patch) and regional levels in the early stage of PWD invasion in South Korea. In addition, we identified the potential factors such as human population density, which affect the dispersal speed of PWD in the different study regions.

\section{Materials and Methods}

\subsection{PWD Occurrence Data}

PWD occurrence data were obtained from the 'Pine Wilt Disease Geographic Information Management System' operated by the Korean Forest Service. The analog maps of PWD occurrence data in 53 regions (i.e., cities, counties, or districts) from 1994 to 2007 were digitalized using ArcView 3.2 and ArcGIS 9.1 (ESRI, Redlands, USA) [17,18]. The dead pine trees were detected by ground survey to define the occurrence area of PWD. The dead trees inside the boundary of the PWD occurrence area in the previous year were considered as trees infected by PWD, whereas the dead trees outside of the boundary were examined for the infection status from the pine wood nematode based on wood samples collected from the trees by nematode experts. PWD occurrence data consisted of polygons without information on the number of trees infected by PWD. To estimate regional dispersal speed, data were selected in 10 regions where the occurrence data were recorded consecutively for at least 5 years (Figure 1). Among them, data from four regions (Gumi, Jinju, Tongyeong and Haman) were from 2001 to 2006, while those in the other six regions (Geoje, Gimhae, Miryang, Busan, Yangsan and Ulsan) were from 2001 to 2005. 
A

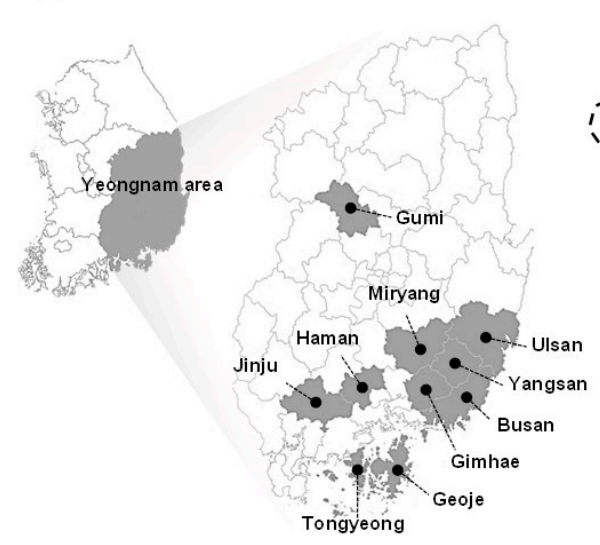

B

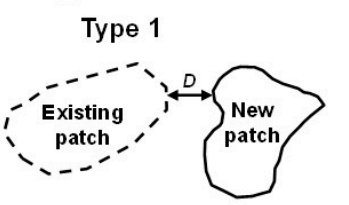

Type 3

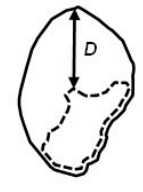

Type 2

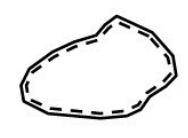

Type 4

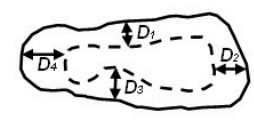

Figure 1. (A) Survey areas and (B) schematic diagrams for four dispersal types of pine wilt disease (PWD). D is the annual dispersal distance of PWD. Type 1: a jumping dispersal from a patch forming a new patch; type 2: without any dispersal; types 3 and 4 are respectively unidirectional and multi-directional dispersals expanding from an existing patch. Dispersal distance of type 4 is a mean of four Ds D1-D4.

To evaluate the factors affecting dispersal speed, we investigated two anthropogenic factors (road density and human population density) and a forestry factor (proportion of coniferous forests in each administrative region). Human population density was obtained from the Korean Statistical Information Service (http: / / www.kosis.go.kr), while road density was estimated from the GIS database as a ratio of the road area to total land area in each study region. The proportion of coniferous forest was estimated as a ratio to the total forest area in each region on the $1 / 25,000$ scale map provided by the Korean Forest Service (http:/ / www.forest.go.kr). We considered coniferous forests to be those areas with at least $25 \%$ coverage area of coniferous species.

\subsection{Dispersal Pattern of Patches}

PWD occurrence areas were recorded in polygons in each year. We considered polygons with a direct connection to another polygon as single patches. A patch cluster was defined as a group of patches with less than $2 \mathrm{~km}$ of uninfected areas between patches. To classify the dispersal pattern of PWD, annual changes in PWD patch shape and dispersal distances within and between the patches were analyzed at the regional level with reference to invasive history. We divided the regions into two groups based on the invasion history: initial stage of invasion if the regions were infested by PWD within the last four years and later stage of invasion if the regions had an invasion history greater than four years. We examined dispersal patterns for all patches between two consecutive years, and obtained approximately 10 different types with different dispersal distance at different directions. To simplify the analyses, we categorized dispersal patterns into four different types based on the shape of the patches. Type 1 is a jumping type of dispersal in which a new patch is formed, consisting of a colony of pine trees infected by the pine wood nematode; type 2 is a patch that does not expand; while types 3 and 4 of dispersal show uni-directional and multi-directional expansion outward from an existing patch (Figure 1). Dispersal distance from patches was estimated according to the dispersal pattern. The dispersal distance of type 1 events was estimated to be the distance between the nearest existing patch and a newly formed patch in two consecutive years (Figure 1), that of type 2 was considered to be $0 \mathrm{~m}$ (Figure 1), that of type 3 was estimated to be the nearest linear distance between the lines of polygons from two consecutive years (Figure 1), and the distance of type 4 was the mean value of dispersal distance of each of the four directional distances between lines of polygons over two consecutive years (Figure 1). We used the term "distance between patch clusters" for the distance between the centers of patch clusters. 


\subsection{Statistical Analysis}

The relationships between dispersal distance and its relative frequency at the regional level were estimated using the exponential decay function [19], showing the best fitting curve based on the CurveExpert (ver. 1.4) [20]:

$$
f(x)=N_{0} e^{-b x}
$$

where $f(x)$ is a frequency at the dispersal distance $(\mathrm{m}) x, N_{0}$ is a frequency at the first smallest dispersal distance (i.e., initial value), and $b$ is the decay constant.

Linear regression analysis was conducted to estimate the relationship between the dispersal distance of PWD and its related environmental factors at the regional level.

\section{Results}

\subsection{Characteristics of Dispersal Patterns}

Of the four dispersal patterns, type 1 was the most dominant (52\% in the data) (Figure 2), followed by types 2,4 and 3, accounting for $27 \%, 12 \%$ and $9 \%$ of dispersal, respectively. In particular, type 1 was dominant in the early stage of the invasion process, and its frequency decreased from the fifth year after the invasion (Figure 2). Dispersal distances between patches were 1.00 and $1.03 \mathrm{~km}$ at the initial and later stages, respectively (Figure 2), while dispersal distances between patch clusters were 1.15 and $0.74 \mathrm{~km}$ at the initial and later stages, respectively (Figure 2).
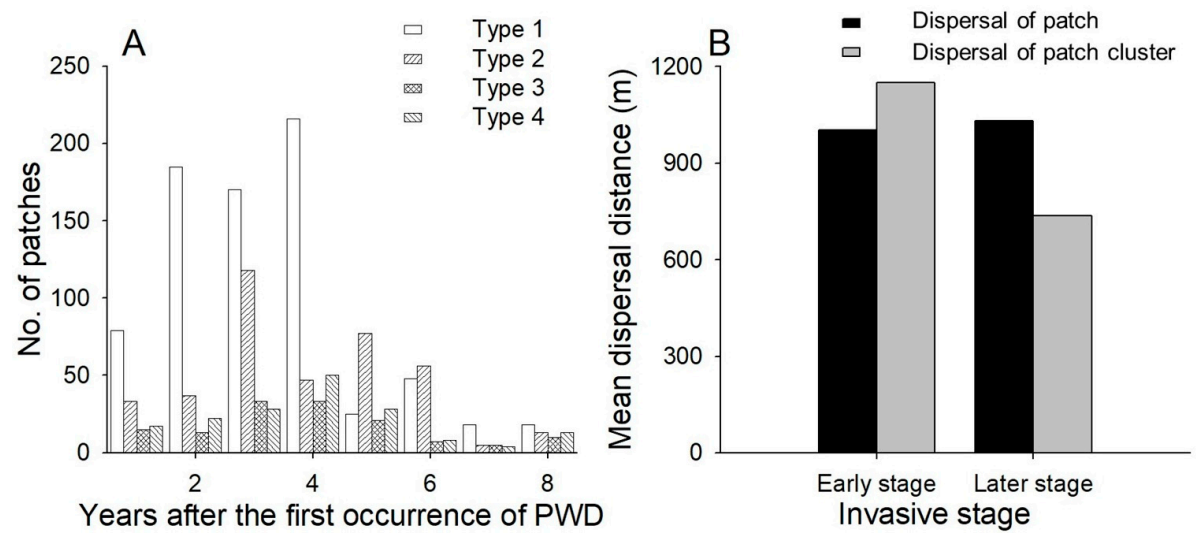

Figure 2. (A) Changes in the proportion of dispersal types according to the number of years after the first occurrence of PWD; (B) Annual dispersal distance at different invasive stages. Early stage: within four years after the invasion; later stage: more than four years after the invasion. Dispersal distance of a patch was measured as D in Figure 1.

\subsection{Annual Dispersal Distance at Patch and Regional Levels}

Most study regions displayed a high frequency of short annual dispersal distance of $0.37 \mathrm{~km}$ at the patch level, while some regions including Geoje, Busan, Ulsan, and Tongyeong displayed a relatively high frequency of long dispersal distance (Figure 3). Overall, $88.8 \%$ of annual dispersal distances were less than $1.0 \mathrm{~km}$ considering all regions together (Figure 3). Only $2.5 \%$ of annual dispersal exceeded $2.0 \mathrm{~km}$, and the maximum annual dispersal distance was $7.71 \mathrm{~km}$ in Geoje (Figure 4).

The relationships between the annual dispersal distance at the patch level and its relative frequency in the ten regions were well fitted by the exponential decay function $\left(R^{2}>0.99\right)$ with regional variations (Figure 3). The slopes of the function were highest in Miryang and lowest in Ulsan. Dispersal greater than $3 \mathrm{~km}$ was observed in Geoje, Gumi and Tongyeong. 


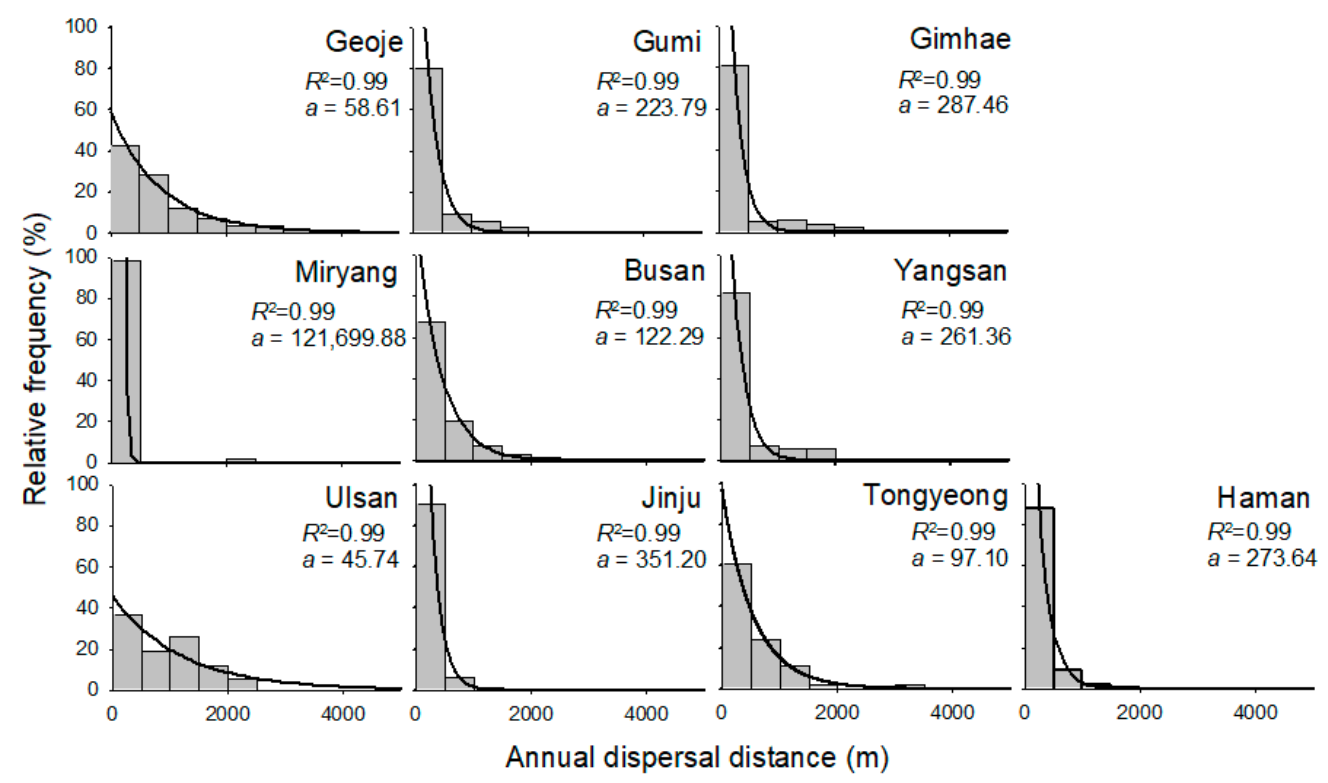

Figure 3. Frequency of annual dispersal distances in ten different study regions: Geoje, Gumi, Gimhea, Miryang, Busan, Yangsan, Ulsan, Jinju, Tongyeong, and Haman. The lines were fitted by the exponential decay function.

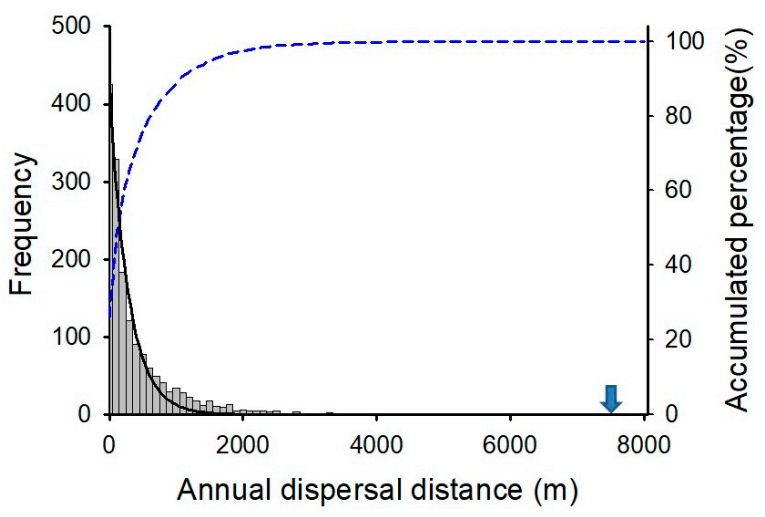

Figure 4. Frequency of annual dispersal distance with pooled data from the ten study regions and its accumulated percentage (dashed line). The solid line was fitted by the exponential decay function. An arrow indicates a maximum value $(7710 \mathrm{~m})$ which is not visualized because of a low frequency value.

Mean annual dispersal distances at the regional level varied by region and year. The longest and shortest mean annual dispersal distances at the regional level were $1.48 \mathrm{~km}$ in Geoje and $0.01 \mathrm{~km}$ in Miryang from 2001 to 2002. Deviations of mean annual dispersal distance between regions $(0.71-0.86 \mathrm{~km})$ were larger than deviations between years $(0.35-0.61 \mathrm{~km})$.

\subsection{Influence of Socio-Environmental Factors}

The human population density, road density, and proportion of coniferous forests all varied by region. Human population density was highest in Busan with 45.7 person/ha and lowest in Miryang with 1.4 person/ha. Road density was highest in Gimhae with $15.9 \%$ of land covered and lowest in Geoje with $4.0 \%$ of land covered. The proportion of coniferous forests was highest in Geoje with $42.5 \%$ and lowest in Gimhae with 23.8\%. Annual dispersal distances increased as a function of the human population density $\left(\mathrm{F}=11.02 ; \mathrm{df}=1,7 ; p<0.013 ; R^{2}=0.61\right)$ (Figure $\left.5 \mathrm{~A}\right)$. However, they were not affected by road density $(\mathrm{F}=0.050 ; \mathrm{df}=1,8 ; p>0.05$ ) (Figure $5 \mathrm{~B}$ ) or proportion of coniferous forests $(\mathrm{F}=0.13 ; \mathrm{df}=1,8 ; p>0.05$ ) (Figure $5 \mathrm{C}$ ). 


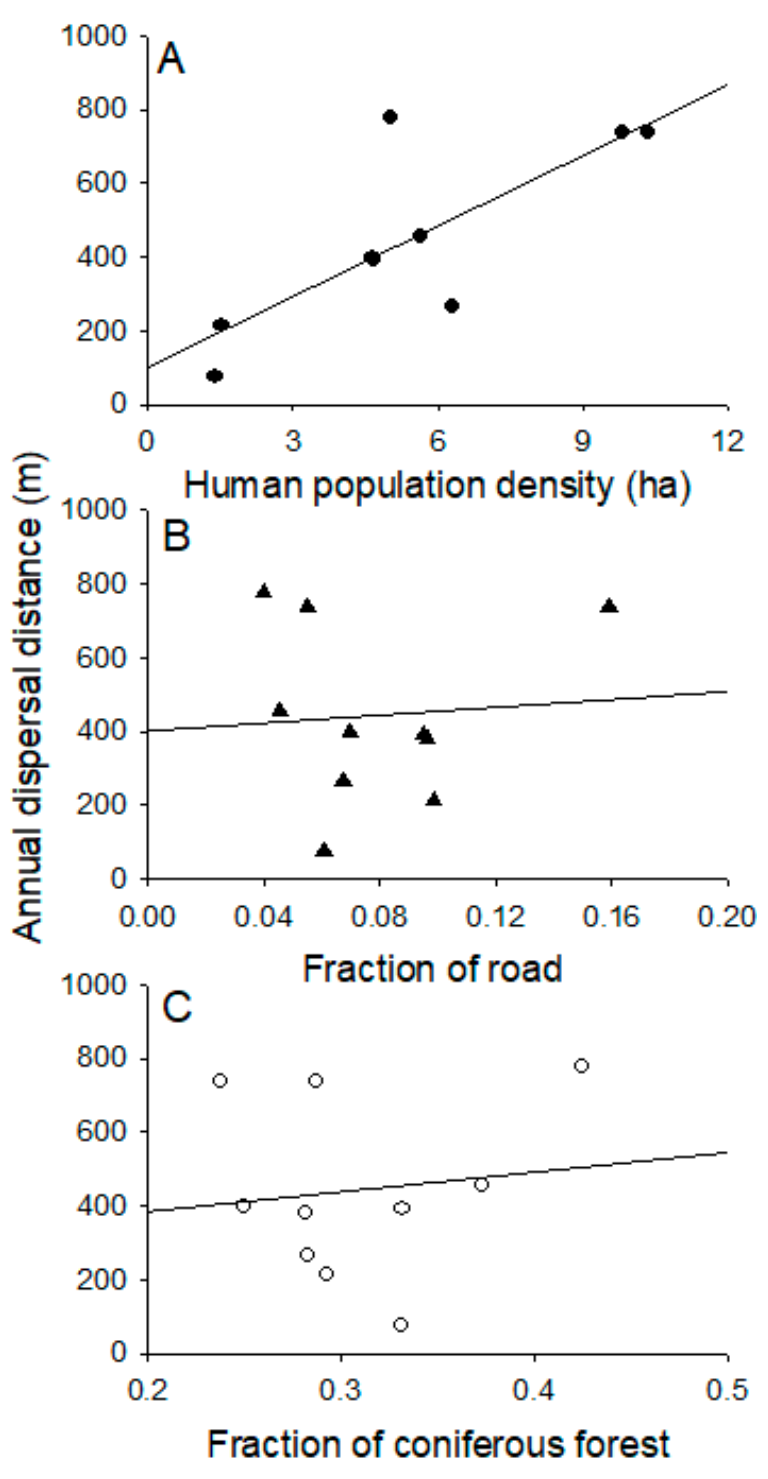

Figure 5. Relationships between annual dispersal distance and (A) human population density; (B) fraction of coniferous forest to total area and (C) fraction of road density to total land cover area.

\section{Discussion}

\subsection{Characteristics of Dispersal Patterns}

Our results showed that the frequency of dispersal patterns changed from a predominance of type 1 (displaying a jumping dispersal forming a new patch) at the early stage of the invasion process to types 3 or 4 (showing a uni- or multi-directional dispersal expanding from an existing patch) at the later stage of the invasion. This phenomenon can be attributed to the foraging behavior of the vector infected by pine wood nematode (PWN). Generally, cerambycid beetles, including Monochamus species, require weakened or freshly dead trees for oviposition. At the initial invasion stage, beetles infected by PWN search for such trees since available oviposition sites are probably limited, causing them to forage over wider areas to find suitable trees. During this foraging behavior, pine trees are infected by the maturation feeding of the adult beetles, and the number of pine trees infected by PWD increases. Beetle female fecundity is maximized if they can find suitable oviposition hosts near where they emerge, but in the early stages of invasion, suitable hosts so close at hand are often not available.

The foraging behaviors of Monochamus species, including M. alternatus, have been intensively studied because these species are the major vectors of PWD in many countries: M. alternatus 
in Japan [21-23], M. galloprovincialis in Europe [14,24,25], and M. carolinensis in America [26]. Flight distances of beetles heavily infected by PWN were shorter than those of lightly infected ones [26]. The beetles forage over broader areas to search for weakened or freshly dead pine trees at the initial stage of the PWN invasion. These foraging behaviors could cause the different spatial distributions of pine trees infected by PWN. Moreover, the proportion of pine trees with delayed symptoms may be different at different stages of the invasion. The proportion of trees with delayed symptoms was higher at the initial stage of the invasion than at the later stage, a phenomenon that might be caused by the lower phoretic pressure of PWN.

Kwon et al. [27] suggested that all pine trees close to trees infected by PWD should be cut to control asymptomatic trees infected by PWD with an optimum clear cut radius of $20 \mathrm{~m}$ at the initial stage of the invasion and $10 \mathrm{~m}$ at the later stage. Our results partially support those of Kwon et al. [27] with respect to the foraging behavior of Monochamus beetles, but the exact radius needed for sanitary clear cutting should be re-examined.

\subsection{Annual Dispersal Distance at Patch and Regional Levels}

The combination of long distance dispersal (LDD) and short distance dispersal (SDD) results in stratified dispersal, including the establishment of new colonies far from the moving population front, growth of individual colonies, and colony coalescence contributing to the advance of the population front [4]. In this study, the annual dispersal distance of $M$. alternatus was $0.37 \mathrm{~km}$ and ranged from 0 to $7.71 \mathrm{~km}$. However, careful interpretation on these dispersal distances is required, for several reasons. The first of these is that the estimation of the dispersal distance on the basis of field observation is spatial scale-dependent. Choi and Park [2] showed that the dispersal speed of PWD in Korea changed from $1.1 \mathrm{~km} /$ year to $13.8 \mathrm{~km}$ /year according to the invasive stage in the nationwide scale. Their dispersal distances were estimated on a relatively large scale based on administrative regions without considering dispersal within the administrative regions, while the dispersal distance in our study was estimated at both patch and regional scales. A second reason is that the dispersal distances include SDD, LDD, and human-mediated dispersal distance. The relative frequency of SDD is higher than those of LDD and human-mediated dispersal distance because $89 \%$ of dispersal distances were less than $1 \mathrm{~km} /$ year. David et al. [14] reported that the mean dispersal distance of M. galloprovincialis, a main European vector of PWD, was $16 \mathrm{~km}$ over the lifetime of the beetle on the basis of flight mill experiments. A modeling study showed that the maximum dispersal distance was $464 \mathrm{~m}$, whereas a lifetime dispersal distance of $M$. galloprovincialis was observed in the range of 107 to $122 \mathrm{~m}$ in the field [25]. Similarly, the dispersal capacity of M. alternatus ranged from 7.1 to $37.8 \mathrm{~m}$ in a P. thunbergii forest about $50 \mathrm{~m}$ in width [23] and the maximum dispersal distance in the forest was $54.9 \mathrm{~m}$ and $58.5 \mathrm{~m}$ for male and female beetles, respectively [22], suggesting that SDDs of Monochamus were a few hundred meters in the field and further dispersal distances might be underestimated. Therefore, the dispersal capacity of M. alternatus in Korea probably ranges from a few hundred meters to a few kilometers with a high probability that any single dispersal would be less than $1 \mathrm{~km}$. Moreover, SDD might be the most dominant dispersal of the beetle and LDD and human-mediated dispersal could be the less frequent. This suggests that preventing longer dispersal by mediating human activity is the best strategy to slow down the dispersal speed of PWD.

The last reason to be cautious about dispersal distances is the potential inconsistency of data collection across studies. All data were collected by each local government of Korea, and the boundary criteria for patches could vary. Moreover, an exact criterion of boundary was not defined during data collection [18]. These factors have the potential to lead to differences in the estimation of occurrence areas in each local government and could induce errors in the estimation of dispersal distance of patches and between patches. In spite of these uncertainties, however, our results showed the dispersal characteristics of PWD in the field condition in spite of potential errors in estimating exact dispersal distances. 


\subsection{Influence of Socio-Environmental Factors on Dispersal}

Interestingly, the dispersal speed of PWD was high in areas with high human population density, suggesting that human-mediated dispersal accelerates the dispersal speed of PWD. The role of human-mediated dispersal in the spread of PWD was also reported in China [28,29]. Human-mediated dispersal plays an important role in the invasion process of many organisms: the emerald ash borer, Agrilus planipennis, in the USA [30], the yellow-legged hornet, Vespa velutina in France [31] and 17 invasive plants in China [32]. Human activities such as logging and trade which require wooden packaging material can increase the risk for the accidental transportation of infected materials by PWN and may be responsible for the rapid spread of the nematode [28]. According to the Korea Forest Service [33], the human-mediated movement of wooden materials infected by PWN was the main cause of new occurrences of PWD in eight administrative regions where the first invasion of PWD was reported in 2013. Besides the movement of wooden material infected by PWN, the accidental movement of beetles vectoring PWD by vehicle may be one of the causes for the rapid dispersal of PWD in Korea. Similarly, adults of walnut husk fly, Rhagoletis completa, were found to be transported passively by vehicles in Europe [34].

In spite of the possibility that beetle movement was facilitated by vehicles, road density was not found to be correlated with the dispersal speed of PWD in our analysis. This might be because our analysis focused on movements within administrative regions on a relatively small scale. In China, long-distance human-mediated dispersal by wooden material infected by PWD was observed, ranging from 111 to $339 \mathrm{~km}$ [28], suggesting that such longer dispersal distance by human-mediated dispersal was not included in our data. In addition, our data reflected only the road density rather than traffic density. Finally, our data were not based on individual trees, but based on the area for the occurrence of PWD. Therefore, estimating the influence of road density on the dispersal speed of PWD was limited by the nature of our data. The influence of the proportion of coniferous forest was not probably observed for similar reasons. Similarly, the dispersal speed of pine needle gall midge (Thecodiplosis japonensis), an invasive pest on pine trees in Korea, was dependent on the density of pine forests in the landscape, with higher speed associated with lower density of pine forest [2]. In highly coniferous forests, insect vectors are more sedentary because favorable feeding conditions are locally abundant.

\section{Conclusions}

The dispersal patterns of PWD were categorized into four types based on the dispersal rate and directions. The dispersal patterns were changed by invasive history from type 1 (i.e., jumping type of dispersal, forming new patches) in the initial stage of invasion to type 4 (multi-directional dispersal outward from an existing patch) in the later stage, suggesting that dispersal through jumping from areas occupied by PWD was the main dispersal route in the early stage of invasion, and human activity plays an important role in the long-term dispersal of PWD. These stratified dispersal patterns could be implemented in the dispersal spatial models in future studies.

Acknowledgments: This study was supported by the National Institute of Forest Science and R\&D Program for Forest Science Technology (Project No. 017042B10-1723-CA01)provided by Korea Forest Service (Korea Forestry Promotion Institute).

Author Contributions: W.I.C. and Y.-S.P. conceived and designed the study; D.S.K., C-Y.L. and J.-B.K. contributed to collect data; W.I.C., H.J.S., D.-S.L., Y.N. and Y.-S. P. analyzed the data; W.I.C, H.J.S., Y.N. and Y.-S.P. wrote the paper.

Conflicts of Interest: The authors declare no conflict of interest. 


\section{References}

1. Mack, R.N.; Simberloff, D.; Lonsdale, W.M.; Evans, H.; Clout, M.; Bazzaz, F.A. Biotic Invasions: Causes, epidemiology, global consequences, and control. Ecol. Appl. 2000, 10, 689-710. [CrossRef]

2. Choi, W.I.; Park, Y.-S. Dispersal patterns of exotic forest pests in South Korea. Insect Sci. 2012, 19, 535-548. [CrossRef]

3. Sharov, A.A.; Leonard, D.; Liebhold, A.M.; Roberts, E.A.; Dickerson, W. “SLOW THE SPREAD” a national program to contain the gypsy moth. J. For. 2002, 100, 30-35.

4. Sharov, A.A.; Liebhold, A.M. Model of slowing the spread of gypsy moth (Lepidoptera: Lymantriidae) with a barrier zone. Ecol. Appl. 1998, 8, 1170-1179. [CrossRef]

5. Hengeveld, B. Dynamics of Biological Invasions; Chapman and Hall: London, UK, 1989; 160p.

6. Tobin, P.C.; Blackburn, L.M. Long-distance dispersal of the gypsy moth (Lepidoptera: Lymantriidae) facilitated its initial invasion of Wisconsin. Environ. Entomol. 2008, 37, 87-93. [CrossRef]

7. Suarez, A.V.; Holway, D.A.; Case, T.J. Patterns of spread in biological invasions dominated by long-distance jump dispersal: Insights from Argentine ants. Proc. Natl. Acad. Sci. USA 2001, 98, 1095-1100. [CrossRef] [PubMed]

8. Chen, H.; Walton, A. Mountain pine beetle dispersal: Spatiotemporal patterns and role in the spread and expansion of the present outbreak. Ecosphere 2011, 2, 1-17. [CrossRef]

9. Jung, C.S.; Koh, S.-H.; Nam, Y.; Ahn, J.J.; Choi, W.I. A forecasting model for predicting the spring emergence of Monochamus saltuarius (Coleoptera: Cerambycidae) on Korean white pine, Pinus koraiensis. J. Econ. Entomol. 2015, 108, 1830-1836. [CrossRef] [PubMed]

10. Togashi, K.; Shigesada, N. Spread of the pinewood nematode vectored by the Japanese pine sawyer: Modeling and analytical approaches. Popul. Ecol. 2006, 48, 271-283. [CrossRef]

11. Wang, Z.; Zhang, Y.; Shi, J.; Luo, Y.-Q.; Ren, L.-L.; Shi, Y.-M. Effect of pine wood nematode invasion on pine community functions in the Pinghu region, Zhejiang Province, Eastern China. For. Sci. Pract. 2013, 15, 302-309. [CrossRef]

12. Abelleira, A.; Picoaga, A.; Mansilla, J.P.; Aguin, O. Detection of Bursaphelenchus xylophilus, causal agent of pine wilt disease on Pinus pinaster in Northwestern Spain. Plant Dis. 2011, 95, 776. [CrossRef]

13. Akbulut, S.; Stamps, W.T. Insect vectors of the pinewood nematode: A review of the biology and ecology of Monochamus species. For. Pathol. 2011, 42, 89-99. [CrossRef]

14. David, G.; Giffard, B.; Piou, D.; Jactel, H. Dispersal capacity of Monochamus galloprovincialis, the European vector of the pine wood nematode, on flight mills. J. Appl. Entomol. 2014, 138, 566-576. [CrossRef]

15. Park, Y.-S.; Chung, Y.-J.; Moon, Y.-S. Hazard ratings of pine forests to a pine wilt disease at two spatial scales (individual trees and stands) using self-organizing map and random forest. Ecol. Inform. 2013, 13, 40-46. [CrossRef]

16. Enda, N. The status of pine wilting disease caused by Bursaphelenchus xylophilus (Steiner et Buhrer) Nickle and its control in Korea. J. Korean For. Soc. 1989, 78, 248-253.

17. Environmental Systems Research Institute (ESRI). ArcGIS 9.1, ESRI: Redlands, CA, USA, 2005.

18. Kim, D.Y. Development of Pine Wilt Disease Spatial Information Management System Using Web-GIS. Master's Thesis, The Graduate School, Kyungil University, Gyeongsan, Korea, 2008. (In Korean).

19. SAS Institute. SAS/STATVR 9.2 User's Guide; SAS Institute: Cary, NC, USA, 2010.

20. Hyames, D. CurveExpert Version 1.4, A Comprehensive Curve Fitting System for Windows; Daniel G. Hyams: Hixson, TN, USA, 2009.

21. Shibata, E. Spatial distribution pattern of the Japanese pine sawyer, Monochamus alternatus Hope (Coleoptera: Cearambycidae), on dead pine trees. Appl. Entomol. Zool. 1984, 19, 361-366. [CrossRef]

22. Shibata, E. Dispersal movement of the adult Japanese pine sawyer, Monochamus alternates Hope (Coleoptera: Cerambycidae) in a young pine forest. Appl. Entomol. Zool. 1986, 21, 184-186. [CrossRef]

23. Togashi, K. A field experiment on dispersal of newly emerged adults of Monochamus alternatus (Coleoptera: Cerambycidae). Appl. Entomol. Zool. 1990, 32, 184-186.

24. Etxebeste, I.; Sanchez-Husillos, E.; Álvarez, G.; Mas i Gisbert, H.; Pajares, J. Dispersal of Monochamus galloprovincialis (Col.: Cerambycidae) as recorded by mark-release-recapture using pheromone traps. J. Appl. Entomol. 2016, 140, 485-499. [CrossRef] 
25. Torres-Vila, L.M.; Zugasti, C.; De-Juan, J.M.; Oliva, M.J.; Montero, C.; Mendiola, F.J.; Conejo, Y.; Sánchez, Á.; Fernández, F.; Ponce, F.; et al. Mark-recapture of Monochamus galloprovincialis with semio chemical baited traps: Population density, attraction distance, flight behavior and mass trapping efficiency. Forestry 2015, 88, 224-236. [CrossRef]

26. Humphry, S.J.; Linit, M.J. Effect of pinewood nematode density on tethered flight of Monochamus carolinensis (Coleoptera: Cerambycidae). Environ. Entomol. 1989, 18, 670-673. [CrossRef]

27. Kwon, T.S.; Shin, J.H.; Lim, J.H.; Kim, Y.K.; Lee, E.J. Management of pine wilt disease in Korea through preventative silvicultural control. For. Ecol. Manag. 2011, 261, 562-569. [CrossRef]

28. Robinet, C.; Roques, A.; Pan, H.; Fang, G.; Ye, J.; Zhang, Y.; Sun, J. Role of human-mediated dispersal in the spread of the pinewood nematode in China. PLoS ONE 2009, 4, e4646. [CrossRef] [PubMed]

29. Robinet, C.; Van Opstal, N.; Baker, R.; Roques, A. Applying a spread model to identify the entry points from which the pinewood nematode, the vector of pine wilt disease, would spread most rapidly across Europe. Biol. Invasions 2011, 13, 2981-2995. [CrossRef]

30. Prasad, A.M.; Iverson, L.R.; Peters, M.P.; Bossenbroek, J.M.; Matthews, S.N.; Sydnor, T.D.; Schwartz, M.W. Modeling the invasive emerald ash borer risk of spread using a spatially explicit cellular model. Landsc. Ecol. 2010, 25, 353-369. [CrossRef]

31. Robinet, C.; Suppo, C.; Darrouzet, E. Rapid spread of the invasive yellow-legged hornet in France: The role of human-mediated dispersal and the effects of control measures. J. Appl. Ecol. 2017, 54, 205-215. [CrossRef]

32. Horvitz, N.; Wang, R.; Wan, F.-H.; Nathan, R. Pervasive human-mediated large-scale invasion: Analysis of spread patterns and their underlying mechanisms in 17 of China's worst invasive plants. J. Ecol. 2017, 105, 85-94. [CrossRef]

33. Korea Forest Service (KFS). Statistical Yearbook of Forestry; Korea Forest Service: Daejeon, Korea, 2014; 473p. (In Korean with English summary)

34. Verheggen, F.; Verhaeghe, A.; Glordanengo, P.; Tassus, X.; Escobar-Gutiérrez, A. Walnut husk fly, Rhagoletis complete (Diptera: Tephritidae), invades Europe: Invasion potential and control strategies. Appl. Entomol. Zool. 2017, 52, 1-7. [CrossRef] 